\title{
FORMANDO PROFESSORES PROFISSIONAIS: resenha do livro "professional capital: transforming teaching in every school
}

\author{
Luiz Gustavo Bonatto Rufino? \\ Samuel de Souza Neto²
}

Hargreaves, Andy; Fullan, Michael. Professional Capital: Transforming Teaching in Every School. Nova York: Teachers College Press, 2012. 220p.

É possível transformar o ofício docente a ponto de possibilitar que professores inseridos nas conjunturas mais diversas consigam ensinar como profissionais? Essa é a pergunta central que baliza a discussão empreendida por dois dos maiores pesquisadores nas ciências da educação atualmente, especialmente no contexto anglófono: Andy Hargreaves ${ }^{3}$ e Michael Fullan 4 , no livro intitulado: "Professional Capital: Transforming Teaching in Every School".

O livro analisa a profissionalização do ensino a partir do conceito de "capital profissional" ('professional capital'), o qual é composto por um conjunto de 3 tipos de capitais: humano ('human capital'), social ('social capital') e de decisão ('decisional capital'). Segundo os autores, o termo capital se refere ao patrimônio (material e imaterial) de uma pessoa ou

\footnotetext{
1 Doutor em Ciências da Motricidade. Unesp Rio Claro - SP. Professor do Centro Universitário de Jaguariúna/SP e das redes públicas municipal de Paulínia/SP e Campinas/SP. Orcid iD: https://orcid.org/0000-0003-2567-9104. E-mail: gustavo_rufino_6@hotmail.com

2 Doutor em Educação pela Universidade de São Paulo - SP. Professor do Programa de PósGraduação em Educação do Instituto de Biociências, Unesp Rio Claro - SP e em Ciências da Motricidade - Unesp Interunidades. Orcid iD: https://orcid.org/0000-0002-8991-7039. E-mail: samuel.souza.neto@gmail.com

3 Doutor em Sociologia pela Universidade de Leeds na Inglaterra. Atuou em diversas instituições inglesas, incluindo a Universidade de Oxford e a Universidade de Nottingham. Co-fundador de diretor do International Center for Educational Change do Ontario Institute for Studies in Education (Canadá). Até 2018 pertenceu à cátedra Thoma More Brennan da Escola de Educação de Lynch do Boston College.

${ }^{4}$ Doutor em Sociologia pela Universidade de Toronto (Canadá). Pesquisador e antigo diretor do Ontario Institute for Studies in Education (Canadá), é diretor do Global Leadership, New Pedagogies for Deep Learning (NPDL.global). Autor de diversos livros, é consultor de organismos internacionais, palestrante, escritor e assessor de reformas educativas.
} 
grupo relacionado aos valores que podem ser aproveitados para se atingir as metas desejadas, indo além da perspectiva financeira. A proposta é avançar sob a perspectiva hegemônica vinculada ao "capital de negócios" ('business capital'). Para os autores, os professores têm que ensinar como profissionais e, inclusive, fazem uma analogia com o discurso esportivo ao repetirem que é necessário se tornar profissional, isto é, um "pro".

Os autores reforçam que a profissionalização não deve permear ações individuais, uma vez que é um intento coletivo. O capital profissional não é uma doação ou presente, mas fruto de conquista. As responsabilidades políticas são grandes e podem criar boas ou más condições, todavia, tratase de algo a ser conquistado pelos próprios professores.

O texto é dividido em 7 capítulos no qual os autores buscam construir sua argumentação de forma a apresentar paulatinamente os conceitos utilizados, bem como contextualizam um panorama geral sobre a profissão docente em diversos locais do mundo. Tem-se um texto de fácil compreensão com o oferecimento de uma quantidade representativa de exemplos práticos que facilitam a leitura, apesar da robustez de referências e da qualidade do referencial teórico utilizado.

No capítulo 1 os autores diferenciam os tipos de capitais: o de negócios ('business') e o profissional ('professional'). O capital de negócios relaciona-se à vinculação dos propósitos da educação atrelados para servir ao grande mercado de investimentos e tecnologia. É a organização baseada no mundo dos negócios, favorecendo uma força de trabalho jovem, flexível, temporária, barata e sem expectativas de aposentadoria.

A segunda perspectiva, apoiada pelos autores, é a que busca desenvolver o capital profissional. É a visão de que a educação é um investimento de longo tempo, relacionado ao desenvolvimento de capital humano. Focaliza boa parte dos investimentos em professores de alto nível e qualidade. Os autores apresentam a composição do capital profissional, atrelando-o ao humano, social e de decisão.

No capítulo 2 os autores reforçam as diferenças entre as visões de capital a partir da apresentação de críticas às avaliações em larga escala e obsessão que alguns sistemas de ensino e governos apresentam pela 
aquisição de dados numéricos. Para eles, performances, scores, resultados e padrões descaracterizam o processo de ensino e aprendizagem, voltado para as relações humanas. Segundo os autores, o ensino acontece em um ambiente específico que apresenta uma cultura centrada no lugar de trabalho. Pensar a profissionalização recai em refletir sobre a escola e a cultura escolar. Eles apresentam três características profissionais: 1) indagarse continuamente sobre o desenvolvimento pessoal; 2) planejar e improvisar o ensino não como um trabalho isolado, mas como parte de um coletivo; 3) ser parte de uma profissão e contribuir para o seu desenvolvimento.

No capítulo 3 os autores analisam de forma mais aprofundada o que é ensinar. Para isso, eles buscam desmistificar certos estereótipos, tais como aqueles que consideram o ensino como 'dom precioso'; 'prática artesanal'; 'lista simples de técnicas'; 'ciência precisa'; 'chamado sagrado', etc. Para romper com esses mitos da profissão, os autores apresentam perspectivas históricas que aludem ao processo de expansão do trabalho docente, bem como às novas demandas que foram sendo inseridas nesse processo. Maiores exigências do Estado e dos pais e um considerável incremento das burocracias fizeram com que os docentes passassem a se sentir sem representação efetiva, sobrecarregados, isolados, jogados à própria sorte.

Segundo os autores, atualmente se reconhece que para se mudar é preciso realmente conhecer os professores, indo além de soluções simples. Quando a porta da sala de aula se fecha, a responsabilidade é do professor. Compreender que essa liderança se constrói por meio do desenvolvimento de seu capital profissional é a proposta dos autores.

No capítulo 4 os autores refletem sobre o que de fato significa ensinar como um profissional. Para isso, eles definem de maneira didática o denominado $5 \mathrm{C}$ que permite o desenvolvimento do capital profissional: Capacidade ou expertise ('capability'); Comprometimento ('commitment'); Carreira ('career'); Cultura ('culture'); Contextos ou condições de ensino ('context or conditions of teaching'). Quando esses ingredientes estão corretos, é possível se ensinar como um "pro".

Os autores analisam os 3 primeiros C, começando pela Capacidade, a qual deve ser compreendida como mais do que uma competência, pois 
requer os mais altos níveis de desempenho em uma tarefa. O segundo se refere ao Comprometimento, um estado emocional, bem como um valor moral. Finalmente, a Carreira está relacionada a visão da pessoa por trás do professor. Conhecer os docentes e suas carreiras é condição fundamental.

Os autores dividem as fases da carreira em três: primeiros anos, meio da carreira (entre 8 e 23 anos de trabalho) e últimos anos. Essa divisão é central para entender a profissionalização, pois cada fase apresenta suas especificidades, apresentando-se algumas implicações: 1) não se deve impor mudanças uniformemente em docentes de fases diferentes, pois os comprometimentos e capacidades variam de acordo com a carreira; 2) é preciso ter um olhar de atenção ao fato de se designar os professores em início de carreira aos contextos mais difíceis, pois isso reforça a lógica do abandono da profissão; 3) deixar com que os professores na fase final da carreira decidam se querem ou não se engajar nas reformas pode ser perigoso, pois seus níveis de comprometimento variam consideravelmente.

No capítulo 5 os autores escrutinam a ideia chave do livro, isto é, analisam os três tipos de capital que compõem o capital profissional. 0 capital humano se refere ao desenvolvimento de conhecimentos, habilidades e competências para ensinar. Conhecer a matéria, como ensiná-la, conhecer as crianças, a diversidade cultural, as práticas de inovação, ter capacidades emocionais e compromisso moral fazem parte das relações humanas presentes na prática pedagógica.

O capital social represente as ações sociais do ensino. Tem a ver com a quantidade e qualidade das interações sociais e relacionamentos entre pessoas e como isso afeta o acesso ao conhecimento, bem como o senso de expectativa, obrigações e confiança e quão longe os docentes podem chegar para aderir às mesmas normas e códigos de comportamento.

Por fim, o capital de decisão é representado pela habilidade de fazer julgamentos com discernimento. Se um professor tem que sempre consultar um manual ou seguir a lição, ele ainda não é um profissional. Juízes tem que julgar mesmo com evidências inconclusivas. Médicos precisam examinar um conjunto de sintomas e decidir sobre um caso. Assim também deve ser com 
os professores. A capacidade de fazer bons julgamentos depende da habilidade de tomar decisões em situações incertas.

Os autores retomam ainda algumas ideias de Donald Schön e reforçam a importância da prática reflexiva para o desenvolvimento dos capitais que compõem essa conjuntura. Para eles, é por meio da reflexão e da capacidade de fazer julgamentos à medida que as situações acontecem que o professor consegue se desenvolver profissionalmente.

No capítulo 6 os autores focam outro eixo do 5C, a Cultura e identificam 6 tipos de cultura profissional partindo de duas grandes categorias: individualista e colaborativa. A individualista é aquela na qual os professores eventualmente recebem feedback de seu trabalho, bem como avaliações periódicas, mas evitam procurar ajuda com medo punições.

Já as culturas colaborativas apresentam grande variabilidade de perspectivas, sendo divididas em 4. A primeira, denominada de "balcanização" representa a fragmentação, se configurando quando os professores se agrupam em pequenos coletivos que compem entre si, procurando posições de supremacia.

A segunda é denominada de "colegialidade forjada", centralizada no maior controle de grupos gestores, os quais procuram organizar e controlar as ações. É caracterizada por atividades formais e procedimentos burocráticos. O maior controle pode fazer com que haja um caminho a ser percorrido e resultados a serem alcançados, embora essa dinâmica elimina em parte a autonomia dos professores.

A terceira cultura colaborativa é intitulada "comunidades de aprendizagem profissional" e apresenta uma dinâmica mais interativa e autônoma de organização. Originalmente essa concepção se referia ao lugar no qual os docentes problematizavam suas práticas, implementando o que aprendiam coletivamente. Todavia, há alguns dilemas, uma vez que se alguém não as estimula, elas tendem a se desfazer. Esse estímulo pode vir de um docente com papel de liderança, mas é frequentemente realizado por um gestor, adquirindo o papel da cultura anterior.

A última forma de organização coletiva se refere aos "aglomerados, redes e federações". Para os autores, da mesma forma que não é salutar 
aos professores trabalhar isolados, as escolas também deveriam agir de forma semelhante. Uma escola isolada pode ter dificuldades que, se partilhadas com as demais de forma democrática, poderia fazer grande diferente na sociedade. Embora possam ser muito efetivas, também podem fomentar a competição ou imposição de visões entre diferentes escolas.

No capítulo 7 e último os autores propõem uma agenda para 0 desenvolvimento do capital profissional, reforçando a necessidade de um processo individual e coletivo de transformação. Eles desenham uma série de proposições baseadas em três instâncias. A primeira se refere aos professores, que devem examinar suas experiências, construindo capital profissional. A segunda se refere às escolas e redes as quais devem promover e desenvolver culturas colaborativas, lideranças sustentáveis ao mesmo tempo em que precisam evitar relações colegiadas restritivas. A terceira se refere aos Estados e organizações internacionais, que devem colaborar com o projeto de profissionalização, rompendo com modelos de gestão burocrática e com a precarização do trabalho.

Ao final, os autores asseveram que há duas escolhas: optar pelo capital de negócios como investimento de curta duração, ou pelo capital profissional que pode realizar mudanças profundas e positivas na sociedade. Os caminhos são esses e a realidade exige severas transformações no ensino.

Desse modo, considera-se que o livro apresenta discussão atual, evidências robustas e argumentações sólidas dentro do campo educativo. Por essas razões, tem-se um material com fortes inclinações a auxiliar professores, escolas, comunidades, bem como políticas públicas e o campo acadêmico nesse árduo projeto de transformar o trabalho docente na perspectiva da profissionalização.

\section{Referencias:}

HARGREAVES, A.; FULLAN, M. Professional Capital: Transforming Teaching in Every School. Nova York: Teachers College Press, 2012. 220p.

Recebida em: 02 de março de 2019

Aprovada em: 20 de agosto de 2019 